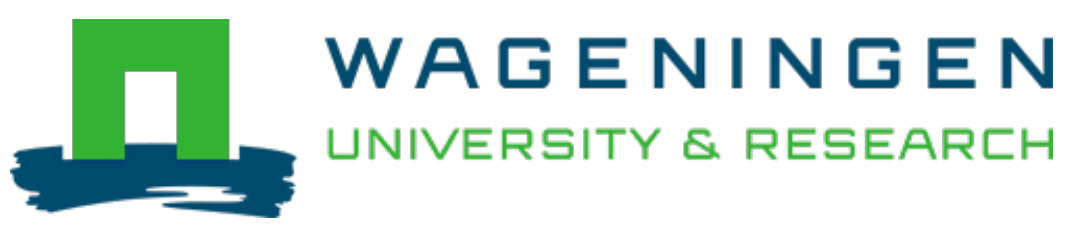

\author{
Molecular binding between anthocyanins and pectic polysaccharides - Unveiling \\ the role of pectic polysaccharides structure \\ Food Hydrocolloids \\ Fernandes, Ana; Oliveira, Joana; Fonseca, Fátima; Ferreira-da-Silva, Frederico; Mateus, Nuno et al \\ https://doi.org/10.1016/j.foodhyd.2019.105625
}

This article is made publicly available in the institutional repository of Wageningen University and Research, under the terms of article $25 \mathrm{fa}$ of the Dutch Copyright Act, also known as the Amendment Taverne. This has been done with explicit consent by the author.

Article 25 fa states that the author of a short scientific work funded either wholly or partially by Dutch public funds is entitled to make that work publicly available for no consideration following a reasonable period of time after the work was first published, provided that clear reference is made to the source of the first publication of the work.

This publication is distributed under The Association of Universities in the Netherlands (VSNU) 'Article $25 \mathrm{fa}$ implementation' project. In this project research outputs of researchers employed by Dutch Universities that comply with the legal requirements of Article $25 \mathrm{fa}$ of the Dutch Copyright Act are distributed online and free of cost or other barriers in institutional repositories. Research outputs are distributed six months after their first online publication in the original published version and with proper attribution to the source of the original publication.

You are permitted to download and use the publication for personal purposes. All rights remain with the author(s) and / or copyright owner(s) of this work. Any use of the publication or parts of it other than authorised under article $25 \mathrm{fa}$ of the Dutch Copyright act is prohibited. Wageningen University \& Research and the author(s) of this publication shall not be held responsible or liable for any damages resulting from your (re)use of this publication.

For questions regarding the public availability of this article please contact openscience.library@,wur.nl 


\title{
Molecular binding between anthocyanins and pectic polysaccharides - Unveiling the role of pectic polysaccharides structure
}

\author{
Ana Fernandes ${ }^{\text {a, * }}$, Joana Oliveira ${ }^{\text {a }}$, Fátima Fonseca ${ }^{\text {b,c }}$, Frederico Ferreira-da-Silva ${ }^{\text {b,c }}$, \\ Nuno Mateus ${ }^{a}$, Jean-Paul Vincken ${ }^{\mathrm{d}}$, Victor de Freitas ${ }^{\mathrm{a}}$ \\ ${ }^{\text {a }}$ REQUIMTE/LAQV, Departamento de Química e Bioquímica, Faculdade de Ciências da Universidade do Porto, Portugal \\ ${ }^{\mathrm{b}}$ i3S - Instituto de Investigaço e Inovaço em Saúde, Universidade do Porto, Portugal \\ ${ }^{c}$ IBMC - Instituto de Biologia Molecular e Celular, Universidade do Porto, Porto, Portugal \\ ${ }^{\mathrm{d}}$ Wageningen University, Laboratory of Food Chemistry, Bornse Weilanden 9, 6708, WG Wageningen, the Netherlands
}

\section{A R T I C L E I N F O}

\section{Keywords:}

Anthocyanins

Cyanidin-3-O-Glucoside

ITC

Pectic polysaccharides

NMR

UV-Visible

\begin{abstract}
A B S T R A C T
The interaction between cyanidin-3-O-glucoside and four citrus pectic fractions was investigated using a combined molecular approach, including isothermal titration calorimetry (ITC), magnetic nuclear resonance (NMR) and UV-Visible spectrophotometry. These pectic fractions differed on their type and degree of esterification (amidated (AHG 30\%), low (HG 30\%) and high methyl esterified fractions (HG 70\%)) and on the pattern of esterification (blockwise (HG-B 70\%) vrs random (HG-R 70\%)). The binding constant $\left(K_{\mathrm{a}}\right)$ and the associated thermodynamic parameters determined showed weak noncovalent interactions, particularly due to electrostatic interactions, hydrogen bonding and hydrophobic effect. The degree and the type of esterification of each pectic fractions had a significant effect on the binding constants determined by ITC and NMR experiments. The binding constants ranged from $10^{2}$ to $10^{4} \mathrm{M}^{-1}$, with the highest $K_{\mathrm{a}}$ value observed for the interaction between cy3glc and low methylesterified fraction, followed by the amidated fraction. Pectic fractions with a higher degree of methyl esterification, resulted on lower binding affinities, with these interactions being mostly driven by hydrophobic effect compared to enthalpy. The different binding affinities could be correlated with anthocyanins colour impact, as a higher red colour intensity could be observed for a cy3glc model solution fortified with a low methylated fraction. However, this colour improvement was not observed for amidated fraction, presumably due to charge repulsive forces, lowering the stability of the flavylium cation.
\end{abstract}

\section{Introduction}

Anthocyanins are water-soluble pigments that are responsible for a great diversity of colours in plants, spanning practically the whole visible spectrum, from orange and red through purple and blue hues (Dangles \& Fenger, 2018). Due to these chromatic features and following the trend of maintaining naturalness of food as far as possible, anthocyanins are attractive candidates to be used as naturally-based colourants. However, natural food colourants such as anthocyanins exhibit a substantially poorer stability during processing and shelf-life, compared to the synthetic dyes (Fernández-López, Angosto, Giménez, \& León, 2013). In fact, anthocyanins colour and stability depends on several factors such as $\mathrm{pH}$, structure and concentration of the pigment, temperature, light, $\mathrm{pH}$, presence of co-pigments, metallic ions or sugars (Ersus \& Yurdagel, 2007). Regarding pH, anthocyanins structural and colour changes result from the switch between different equilibrium forms present in solution: the red flavylium cation $\left(\mathrm{AH}^{+}\right)$at acidic $\mathrm{pH}$, the colorless hemiketal (B) and yellow pale chalcones ( $\mathrm{Cc}$ and $\mathrm{C} t$ ) at slightly acidic $\mathrm{pH}$ and the purple quinoidal base (A) at higher $\mathrm{pH}$ values (Brouillard, 1982; Brouillard \& Delaporte, 1977) (Fig. 1).

In several studies, anthocyanins have been shown to bind to plant cell wall polysaccharides, with this binding being particularly higher for pectin (Lin, Fischer, \& Wicker, 2016; Padayachee et al., 2012; Phan, D'Arcy, \& Gidley, 2016; Phan, Flanagan, D’Arcy, \& Gidley, 2017). In a previous work, through STD-NMR spectroscopy it was observed a greater anthocyanin-pectin binding for anthocyanins bearing more hydroxyl groups, clearly suggesting the importance of specific anthocyanins structural features for these bindings (Fernandes, Brás, Mateus, \& de Freitas, 2014; Fernandes, Ivanova, 2014). As a result of anthocyanins-polysaccharides interactions, anthocyanins colour,

\footnotetext{
* Corresponding author.

E-mail address: ana.fernandes@fc.up.pt (A. Fernandes).
} 
extractability, chemical stability and in vitro gastric stability, and were significantly improved (Buchweitz, Speth, Kammerer, \& Carle, 2013a, 2013b; Fernandes, Brás, Oliveira, Mateus, \& de Freitas, 2016; Hernández-Hierro et al., 2014; Koh, Xu, \& Wicker, 2020b; Padayachee et al., 2013). For instance, the colour stability of blackcurrant anthocyanins was significantly improved by different pectins from citrus, apple and sugar beet (Buchweitz et al., 2013a), while blueberry pectin improved the in vitro gastric stability of several anthocyanins (Koh et al., 2020b). The multiple studies regarding pectin-anthocyanins interactions reflect the high variability and complexity of these interactions with these being strongly dependent on the fine structure of both anthocyanins and pectins.

Pectic polysaccharides are heterologous polymers (Watrelot, Le Bourvellec, Imberty, \& Renard, 2013) commonly recognized as having three major covalently linked structural regions such as homogalacturonans (HG) and rhamnogalacturonans (RGI and RGII) (Caffall \& Mohnen, 2009; De Vries, Rombouts, Voragen, \& Pilnik, 1982; Mohnen, Doong, Liljebjelke, Fralish, \& Chan, 2003). Homogalacturonans correspond to about $60 \%$ of plant cell wall pectic polysaccharides with these structures being composed of a linear polymer of a $\alpha-1 \rightarrow 4$ linked galacturonic acid chains ( $\alpha$-D-GalpA), partially methyl esterified and/or acetylated (Thibault, Renard, Axelos, Roger, \& Crépeau, 1993; Voragen, Coenen, Verhoef, \& Schols, 2009). RG I and II are more branched pectin domains, composed of additional monosaccharides such as rhamnose, galactose or arabinose (Yapo, Lerouge, Thibault, \& Ralet, 2007). Pectin fine structure, particularly the degree of methylesterification on the $\mathrm{C}_{6}$ of GalpA in the homogalacturonan region, the distribution of charges in the backbone and the average molecular weight of the polymer, strongly influence the polysaccharide's physicochemical properties and functionality (Cameron, Chau, Hotchkiss, \& Manthey, 2017). For instance, the degree of methylesterification (DM) is of great importance in determining pectin polyanionic nature, which affects the hydrophobicity of the polymer and thereby modulating their interaction with other biomolecules and associated functional properties (Watrelot et al., 2013). In addition to DM, the distribution pattern of non-methyl esterified GalpA units has been hypothesized to have an important role in the cation binding capacity of pectin (Voragen et al., 2009), with blocks of more than 10 non-esterified GalpA residues yielding pectin molecules that are sensitive to cations cross-linking. On the other hand, amidated pectic polysaccharides can also modulate its functionalities as an ingredient (Mortensen et al., 2017).

Isothermal titration calorimetry (ITC) is a powerful and attractive technique for the study of biomolecular interactions, providing direct thermodynamic information in solution, even for low binding affinity systems. In fact, from a single experiment, ITC allows the determination of association constants $\left(K_{\mathrm{a}}\right)$, stoichiometry $(n)$, free energy $(\Delta \mathrm{G})$, enthalpy $(\Delta \mathrm{H})$ and entropy $(\Delta \mathrm{S})$ of binding, therefore providing a wealth of important data (Turnbull \& Daranas, 2003). ITC has been used to characterize the binding between procyanidins with various degrees of polymerization and galloylated tannins with pectic polysaccharides fractions with promising results (Mamet, Ge, Zhang, \& Li, 2018; Watrelot et al., 2013; Watrelot, Le Bourvellec, Imberty, \& Renard, 2014). However, to the best of our knowledge, this methodology has not been applied to study the molecular interaction between anthocyanins and pectic polysaccharides.

In this research, it was intended to study the molecular interactions between cyanidin-3-O-glucoside (a representative model anthocyanin) and pectic polysaccharides with different degrees and pattern of methyl esterification and amidation. The main goals of this work are to establish a pectin structure-function relationship related to anthocyanins interaction and to assess the impact of these interactions for the modulation of anthocyanins colour features. This is a fundamental issue for anthocyanins-pectin interaction as the knowledge of the nature and consequences of these noncovalent interactions should greatly contribute to the design of specific anthocyanins stabilization tools. An innovative approach, combining ITC, NMR and UV-Visible spectroscopy was used to probe the binding affinity, the thermodynamic nature of anthocyanin-pectic polysaccharides bindings and cy3glc chromatic features modifications due to interaction.

\section{Experimental section}

\subsection{Materials}

All chemicals used in this work were all analytical or HPLC grade. General chemicals such as citric acid, sodium citrate, sodium chloride were obtained from Sigma-Aldrich ${ }^{\circ}$. Reverse-phase C-18 silica gel (LiChroPrep ${ }^{\circledR}$, RP-18; 40-63 $\mu \mathrm{m}$ ) was obtained from Merck KGaA. Acetonitrile was obtained from Panreac Quimica, methanol and formic acid from Chem-Lab NV and ethanol from AGA.

\subsection{Pectic polysaccharides}

Four commercial pectic polysaccharides fractions obtained from citrus fruits were supplied from CP-Kelco ${ }^{\circledR}$ and kindly donated by Dr. Jean-Paul Vincken (WU Agrotechnology \& Food Science, Wageningen, The Netherlands). These polysaccharide fractions included a low methyl esterified fraction (degree of methyl esterification of 30\% - HG 30\%), a low amidated fraction (degree of methyl esterification of 30\% - AHG $30 \%$ ) and two high methyl esterified fractions (degree of methyl esterification of 70\% - HG 70\%). These two last fractions differed on the pattern of methyl esterification, namely one with a random distribution of the methyl esters (HG-R 70\%) and another with a blockwise distribution along the pectin chain (HG-B 70\%). Neutral sugars and uronic acids were quantified by gas chromatography (Englyst \& Cummings, 1984) and colorimetrically (De Ruiter, Schols, Voragen, \& Rombouts, 1992), respectively. These fractions were characterized by high galacturonic acid content $(92 \mathrm{~mol} \%)$ with the remaining $8 \mathrm{~mol} \%$ equally distributed over arabinose, galactose and rhamnose.

\subsection{Anthocyanins extraction and purification}

Blackberry fruits (Rubus fruticosus L.) were selected as anthocyanin source due to cyanidin-3-O-glucoside (cy3glc) high amounts and purity. Blackberries were kindly provided by Verdes Quimeras Ltd. Cy3glc was extracted from crushed blackberries fruits through methanolic solution

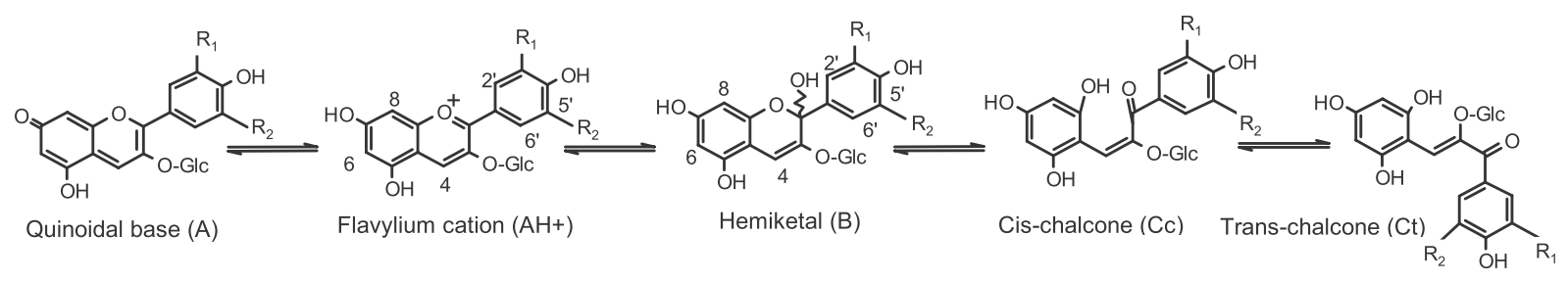

Fig. 1. Network of the equilibrium forms of anthocyanins (cyanidin-3-O-glucoside, $\mathrm{R}_{1}=\mathrm{OH}, \mathrm{R}_{2}=\mathrm{H}$ ). 
$(1: 1 ; \mathrm{v} / \mathrm{v} ; 0.1 \mathrm{M} \mathrm{HCl})$, under shaking for $24 \mathrm{~h}$. The resulting anthocyaninrich extract was filtered through a nylon membrane and subsequently concentrated on a rotary evaporator under vacuum. Cy3glc was isolated from the anthocyanin-rich extract by reverse-phase C-18 silica gel with $10 \%$ methanol acidified solution. After solvent evaporation, cy3glc was lyophilized and stored at $-18{ }^{\circ} \mathrm{C}$ until further use. Cy3glc purity was checked by HPLC-DAD/ESI-MS and through ${ }^{1} \mathrm{H}$ NMR spectroscopy.

\subsection{Isothermal titration calorimetry}

The enthalpy changes and the binding parameters associated with anthocyanin-pectic polysaccharides interactions was measured on a VPITC MicroCalorimeter at $298 \mathrm{~K}$ controlled by Origin 7.0 VPViewer. To allow the comparison between the different pectic polysaccharide fractions, concentrations were expressed relative to the main pectic monomer, i.e. galacturonic acid (Watrelot et al., 2013; Watrelot et al., 2014). Cy3glc and pectic polysaccharides were dissolved separately in Milli-Q ultrapure water $\mathrm{pH} 3.4$ (acidified with $\mathrm{HCl}$ ) and were left under magnetic stirring at room temperature for at least $12 \mathrm{~h}$ to ensure total pectic polysaccharide dissolution and anthocyanin $\mathrm{pH}$ equilibration. Anthocyanin and pectic polysaccharide solutions were degassed prior to the titration. To obtain a hyperbolic curve, as recommended for low affinity systems (Turnbull et al., 2003), different anthocyanin and pectic polysaccharides concentrations were tested. Anthocyanin solution (1.0 $\mathrm{mM}$ ) was loaded into the calorimeter sample cell $(1.4 \mathrm{~mL})$ and the pectic polysaccharides (titrant - $39 \mathrm{mM}$ galacturonic acid equivalents) were loaded into the injection syringe and titrated into the sample cell (cyanidin-3-O-glucoside) by injections of 5,15 or $20 \mu \mathrm{L}$ aliquots (10.0, 30.0 and $40.0 \mathrm{~s}$ injection duration, respectively), depending on the anthocyanin-pectic polysaccharide interacting system. The time delay (to allow equilibration) between successive injections was of $400 \mathrm{~s}$. The sample cell content was stirred throughout the experiments at $394 \mathrm{rpm}$ to ensure thorough mixing.

Raw data obtained as a plot of heat flow (microcalories per second) against time (minutes) were integrated peak-by-peak and normalized to obtain a plot of observed enthalpy change per mole of injectant $(\Delta H$, kcal.mol ${ }^{-1}$ ) against the molar ratio (galacturonic acid/cyanidin-3-Oglucoside). Baseline establishment and peak integration was performed using NITPIC software while the experimental data were fitted to a theoretical titration curve using SEDPHAT software (Keller et al., 2012; Scheuermann \& Brautigam, 2015), with enthalpy change $(\Delta \mathrm{H})$ and association constant $\left(K_{\mathrm{a}}\right)$ as adjustable parameters. Thermogram were made using GUSSI software as described in the literature (Brautigam, 2015). The other thermodynamic parameters $(\Delta G$ and $\Delta S)$ were calculated from the van't Hoff equation (eq. (1)):

$\Delta G=-R T \ln K_{a}=\Delta H-T \Delta S$

\subsection{UV-visible analysis of anthocyanin-pectic polysaccharides interactions}

A spectrophotometric method was used to study anthocyanins colour modification due to pectic polysaccharides-anthocyanin interactions. Stock solutions of each pectic polysaccharide sub-fractions and cyanidin-3-O-glucoside were prepared in a $10 \mathrm{mM}$ citrate buffer solution $(\mathrm{pH}$ 3.4 ) at $24 \mathrm{mM}$ galacturonic acid equivalents and $1.0 \mathrm{mM}$, respectively. The ionic strength was adjusted to $25 \mathrm{mM}$ through the addition of sodium chloride. Each anthocyanin/pectic polysaccharides mixture was prepared by mixing a constant volume of cy3glc solution $\left(10^{-4} \mathrm{M}\right)$ with increasing amounts of each pectic polysaccharides solution to give the required pectic polysaccharide concentration of 2.0; 5.0; 10.0 and 15.0 $\mathrm{mM}$ galacturonic acid equivalents. Control spectra were obtained for cy3glc solution and for each pectic polysaccharide concentration tested alone. Each experiment was performed in triplicate and all solutions were left to equilibrate for $30 \mathrm{~min}$ at room temperature before spectroscopic measurements. The absorbance values were collected at the maximum absorption wavelength of free cyanidin-3-O-glucoside at $\mathrm{pH}$ $3.4\left(\lambda_{\max }=516 \mathrm{~nm}\right)$. UV-visible spectra were recorded at $25^{\circ} \mathrm{C}$, in $1 \mathrm{~nm}$ steps from 360 to $860 \mathrm{~nm}$ on a Bio-Tek Power Wave XS spectrophotometer, equipped with Gen5 Software (Fernandes et al., 2016).

\section{6. ${ }^{1}$ H NMR studies}

For the ${ }^{1} \mathrm{H}$ NMR studies, $1.0 \mathrm{mM}$ of cyanidin-3-O-glucoside solution was prepared in $\mathrm{D}_{2} \mathrm{O}$, $\mathrm{pD}$ was adjusted to $3.4 \mathrm{pD}=\mathrm{pH}$-meter reading for solutions in $\mathrm{D}_{2} \mathrm{O}+0.40$ ) with $\mathrm{DCl}$ and transferred into $5 \mathrm{~mm}$ NMR tubes. $\mathrm{pH}$ measurements were made in a pH-meter WTW $\mathrm{pH} 320$ fitted with a standard glass Crison ${ }^{\circledR} 5209$ electrode. The calibration was made with standard aqueous buffers at $\mathrm{pH} 4.0$ and $\mathrm{pH} 1.0$ from Crison ${ }^{\circledR}$ and the conventional $\mathrm{pD}$ scale from glass electrode readings, was obtained as reported in the literature (Popov, Rönkkömäki, \& Lajunen, 2006). Sodium trimethylsilyl-[2,2,3,3-d4]-propionate (TSP) was used as an internal standard for chemical shift measurements ( $5 \mu \mathrm{L}$ TSP $2 \mathrm{mg} \mathrm{mL}^{-1}$ in $\mathrm{D}_{2} \mathrm{O}$ ). After cy3glc spectrum acquisition, pectic polysaccharide solutions (24 mM galacturonic acid equivalents) in $\mathrm{D}_{2} \mathrm{O}$ (at $\mathrm{pH}$ 3.0), were independently titrated into the anthocyanin solution (1-7 $\mu \mathrm{L}$ volumes added) and NMR spectra were acquired at each titration point. All ${ }^{1} \mathrm{H}$ NMR spectra were acquired at $298 \mathrm{~K}$ on a Bruker Avance III $600 \mathrm{HD}$ spectrometer, operating at $600.13 \mathrm{MHz}$, equipped with $5 \mathrm{~mm}$ CryoProbe Prodigy and pulse gradient units, capable of producing magnetic field pulsed gradients in the z-direction of $50 \mathrm{G} / \mathrm{cm}$. The measurements were done with standard Bruker pulse sequences at $298 \mathrm{~K}$. ${ }^{1} \mathrm{H}$ NMR experiments were performed with water suppression using excitation sculpting with gradients, acquisition time $1.70 \mathrm{~s}$, relaxation delay $2 \mathrm{~s}$ and 128 transients of a spectral width of $8000 \mathrm{~Hz}$ collected into32 $\mathrm{K}$ time domain points.

\subsection{NMR data analysis}

For the titration experiments, chemical shifts of individual assigned resonances of cy3glc flavylium cation protons were analyzed as a function of pectic polysaccharides concentration. Chemical shift data were used to calculate the association constant $\left(K_{d}\right), n$ and the maximum chemical shift change $\left(\Delta \delta_{\max }\right)$ for cy3glc protons using the equation previously described, considering a binding equilibria at $n$ multiple equivalents sites (eq. (2)) (Charlton et al., 2002):

$\Delta \delta=\frac{\Delta \delta_{\max }}{2}\left\{\left(1+\frac{K_{d}}{n[A]}+\frac{[P]}{n[A]}\right)-\left[\left(1+\frac{K_{d}}{n[A]}+\frac{[P]}{n[A]}\right)^{2}-4 \frac{[P]}{n[A]}\right]^{1 / 2}\right\}$

where $\Delta \delta$ is the chemical shift change (ppm), $\Delta \delta_{\max }$, maximum change in chemical shift (ppm), $K_{\mathrm{d}}$, dissociation constant $(\mathrm{M}),[\mathrm{A}]$, total anthocyanin concentration (M) and [P], total concentration of each pectic polysaccharide fraction (M galacturonic acid equivalents). Values of $K_{\mathrm{d}}, n$ and $\Delta \delta_{\max }$ were calculated using a least-squares-fitting routine within the software program Microsoft EXCEL.

\subsection{Statistical analysis}

Analysis were performed in triplicates and the values obtained were expressed as mean values and standard deviation (SD). Statistical significance was detected by analysis of variance (ANOVA), followed by the Tukey's test; Differences were considered to be statistically significant at $p<0.05$. All statistical data were processed using GraphPad Prism version 5.0 for Windows.

\section{Results and discussion}

In the present work, ITC and NMR methodologies were employed to characterize the binding affinity and the thermodynamic parameters associated to anthocyanin-pectic polysaccharides interactions at $25^{\circ} \mathrm{C}$. UV-Vis was also used to check the possible colour modifications of 
anthocyanin solutions due to association with pectic polysaccharides. Anthocyanin-pectic polysaccharides interactions were studied in acidic aqueous solutions at $\mathrm{pH}$ close to 3.4 , since this is the typical $\mathrm{pH}$ of some food products rich in anthocyanins, particularly red fruits juices.

\subsection{Thermodynamic characterization of anthocyanin-pectic polysaccharide associations}

ITC microcalorimetry was used to investigate the binding affinity and the enthalpy changes associated to cy3glc-pectic polysaccharides interactions. The resulting data of cy3glc titration by pectic polysaccharides were plotted as molar enthalpy changes against molar ratio. Control experiments for polysaccharides fractions (injections of pectic polysaccharides into aqueous acidic solution) and for cy3glc (titration by aqueous acidic solution), yielded small endothermic peaks. Fig. 2 shows the ITC thermogram and the binding isotherms of cy3glc titration by pectic polysaccharides fractions (after subtraction of polysaccharide control experiment). These types of ITC curves was observed for the interaction of pectic polysaccharides with other flavonoids, namely for condensed tannins and galloylated tannins (Mamet et al., 2018; Watrelot et al., 2013; Watrelot et al., 2014). Titration of cy3glc by each polysaccharide fraction resulted on exothermic peaks (Fig. 2). Due to the general shape of the binding isotherms it could also be assumed that anthocyanins interact nonspecifically with pectic polysaccharides rather than binding to specific sites, as the binding isotherms do not exhibit the sigmoidal shape expected for a specific interaction (Frazier,
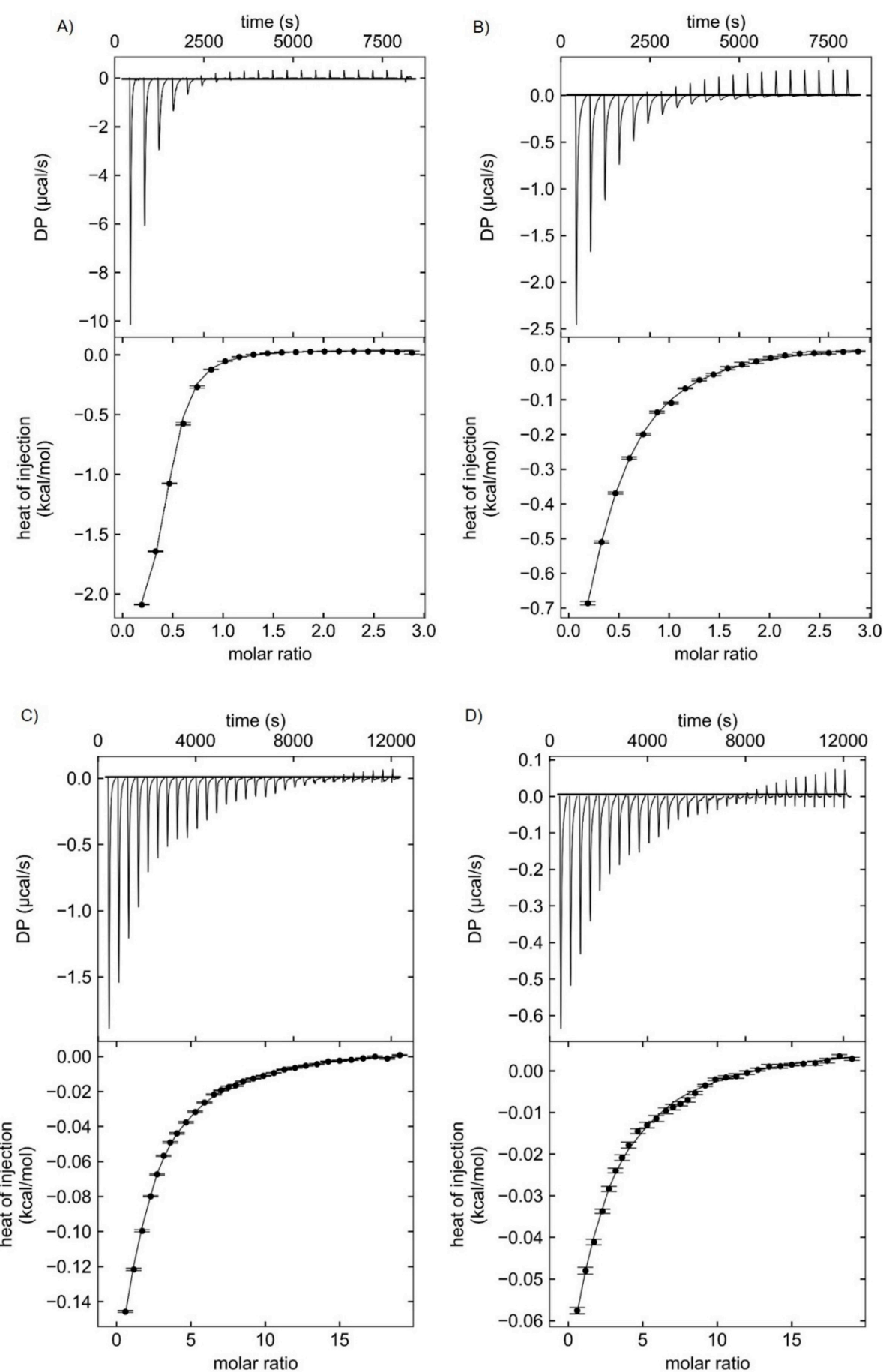

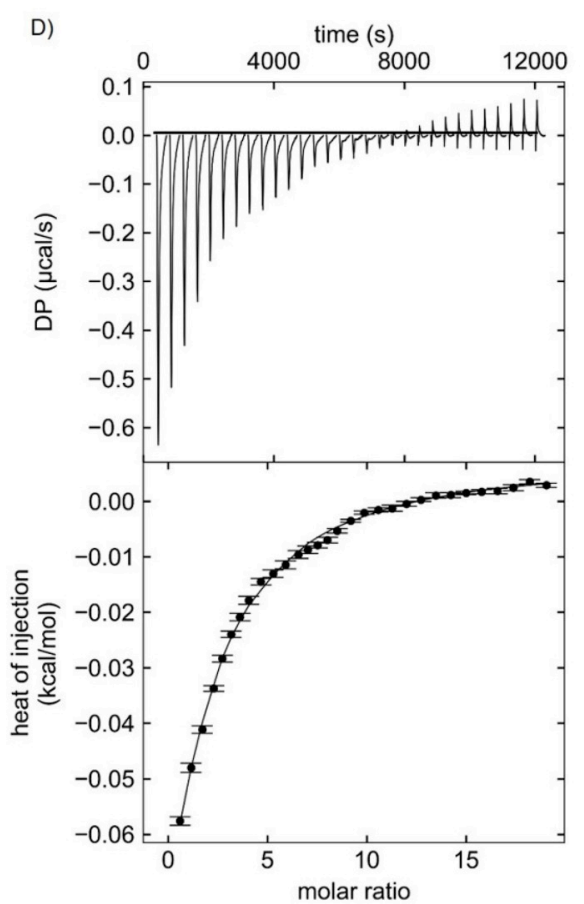

Fig. 2. ITC titration of cyanidin-3-O-glucoside (1.0 $\mathrm{mM}$ ) with the different pectic polysaccharides fractions (39 $\mathrm{mM}$ galacturonic acid equivalents): thermogram (top); binding isotherms (dots) and one-site fitting curves (line) against pectic polysaccharide/ cy3glc molar ratio after peak integration (bottom) using SEDPHAT software; A) (HG 30\%, low methylesterified; AHG 30\%, amidated low methylesterified; HG-B 70\%, high methylesterified blockwise; HG-R 70\%, high methylesterified random), at pH 3.4 and 298.15 K. Experiments were performed in triplicate. 
Papadopoulou, Mueller-Harvey, Kissoon, \& Green, 2003). While titration of cy3glc by low methylesterified fractions (HG and AHG) resulted in stronger exothermic peaks (heat released -10 and $-2.5 \mu \mathrm{cal} / \mathrm{s}$, respectively) for the first injections and endothermic peaks after saturation, titration with pectic fractions with higher degree of esterification yielded weaker exothermic peaks (heat released -1.5 and $-0.6 \mu \mathrm{cal} / \mathrm{s}$, for HG-B and HG-R 70\%, respectively). These ITC binding curves were further analyzed by fitting the data with SEDPHAT software, using one-site binding model. This binding model was also used to study tannin-pectic polysaccharides interactions, providing good results (Watrelot et al., 2013; Watrelot et al., 2014). The thermodynamic parameters obtained from the analysis of the fitting of the ITC binding isotherms are shown in Table 1, along with the derived thermodynamic parameters of $\Delta \mathrm{G}$ and $-\mathrm{T} \Delta \mathrm{S}$.

The affinity constant $\left(K_{\mathrm{a}}\right)$ obtained by ITC presented a wide range of values from $10^{2}$ to $10^{4} \mathrm{M}^{-1}$, with the highest $K_{\mathrm{a}}$ value observed for the interaction between cy3glc and low methylesterified pectic polysaccharides fraction $\left(2.5 \times 10^{4} \mathrm{M}^{-1}\right.$ for HG $\left.30 \%\right)$. For the amidated homogalacturonan fraction an association constant one order of magnitude lower was obtained $\left(4.2 \times 10^{3} \mathrm{M}^{-1}\right.$ for AHG). Considering the interaction between high methyl esterified pectic polysaccharides (HG-B and HG-R 70\%) and cy3glc, the affinity constants obtained where much lower and there were no statistical differences between these two fractions. This seemed to indicate a higher binding affinity between cy3glc and low methylesterified pectic polysaccharides than with high methylesterified, showing the importance of the degree of methylation of pectic polysaccharides on their ability to interact with cyanidin-3-Oglucoside, as higher affinity could be observed for deesterified homogalacturonan backbones, where a high content of free carboxyl groups from galacturonic acid residues occur. These results were different from those observed for the binding interaction between highly polymerized procyanidins fractions and galloylated procyanidins with pectic polysaccharides, presenting a higher binding affinity with highly methylated pectic polysaccharides essentially due to hydrophobic effect (Mamet et al., 2018; Watrelot et al., 2013). For anthocyanins, the binding with pectic polysaccharides is $\mathrm{pH}$ dependent (Koh, Xu, \& Wicker, 2020a; Lin et al., 2016; Phan et al., 2017). At slightly acidic solutions (such as at pH 3.4), the positively charged flavylium cation is in equilibrium with the neutral hemiketal form, the chalcone forms and the quinoidal bases. According to the data published by Leydet et al., at $1.0 \mathrm{mM}$ of cy3glc, the $\mathrm{p} K_{\mathrm{h}}$ should be approximately 3.5 (Leydet et al., 2012). At this $\mathrm{pH}, 50 \%$ of anthocyanins are likely to occur as flavylium cation and the other $50 \%$ as neutral hemiketal form and quinoidal bases (see Fig. 1). On the other hand, at the apparent pectin $\mathrm{p} K \mathrm{a} \approx 3.5-4.0$ value, free carboxyl groups may be partially deprotonated, bearing a negative charge, thereby possessing the ability to interact with flavylium cations. Thus, at

Table 1

Thermodynamic parameters (association constants, $K_{\mathrm{a}}$, enthalpy, $\Delta \mathrm{H}$, Gibbs energy, $\Delta \mathrm{G}$ and entropy, -T $\Delta S$, determined by ITC for the binding of cyanidin-3$O$-glucoside and each pectic polysaccharide (HG 30\%, low methylesterified; AHG 30\%, amidated low methylesterified; HG-B 70\%, high methylesterified blockwise; HG-R 70\%, high methylesterified random), at pH 3.4 and $298.15 \mathrm{~K}$. Fitting confidence: $p>0.95$. Columns with different letters are statistically different.

\begin{tabular}{cllll}
\hline \multicolumn{5}{c}{ Cyanidin-3-O-glucoside } \\
\cline { 2 - 5 } & $K_{\mathrm{a}}\left(\mathrm{M}^{-1}\right)$ & $\begin{array}{l}\Delta \mathrm{H}(\mathrm{kJ} . \\
\left.\mathrm{mol}^{-1}\right)\end{array}$ & $\begin{array}{l}\Delta \mathrm{G}(\mathrm{kJ} . \\
\left.\mathrm{mol}^{-1}\right)\end{array}$ & $\begin{array}{l}-\mathrm{T} \Delta \mathrm{S}(\mathrm{kJ} . \\
\left.\mathrm{mol}^{-1}\right)\end{array}$ \\
\hline HG 30\% & $2.5 \times 10^{4} \pm 2.2 \times$ & $-9 \pm 2^{a}$ & $-25.1 \pm$ & $-16 \pm 1^{a}$ \\
& $10^{3 a}$ & & $0.2^{a}$ & \\
AHG & $4.2 \times 10^{3} \pm 1.5 \times$ & $-9 \pm 2^{a}$ & $-20.3 \pm$ & $-11 \pm 3^{a}$ \\
$30 \%$ & $10^{3 b}$ & & $0.8^{b}$ & \\
HG-B & $6.2 \times 10^{2} \pm 2.4 \times$ & $-4 \pm 1^{b}$ & $-16 \pm 1^{c}$ & $-12 \pm 2^{a}$ \\
$70 \%$ & $10^{2 c}$ & & & $-15 \pm 3^{a}$ \\
HG-R & $1.3 \times 10^{3} \pm 1.7 \times$ & $-1.2 \pm 0.5^{c}$ & $-16 \pm 2^{c}$ & -15 \\
$70 \%$ & $10^{2 c}$ & & & \\
\hline
\end{tabular}

$\mathrm{pH}$ 3.4, electrostatic interaction is an important mechanism for anthocyanin-pectic polysaccharides binding. Additionally, hydrogen bonds can also be formed with the functional groups of the galacturonic acid, decreasing from amide groups $\left(\mathrm{CONH}_{2}\right)$ to carboxylic groups $(\mathrm{COOH})$ and methyl esters $\left(\mathrm{COOCH}_{3}\right)$, which could explain the higher binding affinity of the low esterified fractions to cyanidin-3-O-glucoside (Buchweitz et al., 2013a).

For all interacting systems, the Gibbs free energy $(\Delta G)$ was negative, which demonstrated that the interaction between these biomolecules was thermodynamically favorable. These values where less negative for the interaction between cyanidin-3-O-glucoside and high methylated pectic polysaccharides, reflecting he lower binding affinity for these polysaccharides fractions. Gibbs free energy was quite weak, ranging from -25 to $-16 \mathrm{~kJ} \mathrm{~mol}^{-1}$, which is much lower than the value for covalent bond formation (approximately $400 \mathrm{~kJ} \mathrm{~mol}^{-1}$ ), demonstrating that non-covalent binding occurred (Cahyana \& Gordon, 2013), even though being higher than the $\Delta G$ values reported for the interaction between procyanidins and commercial pectic polysaccharides $(-5.4 \mathrm{~kJ}$ $\mathrm{mol}^{-1}$ ) (Watrelot et al., 2013).

The interaction between anthocyanins and pectic polysaccharides is highly complex and the interpretation of the thermodynamic changes and driving forces involved in these bindings is for that extremely challenging. At pH 3.4, electrostatic interactions hydrophobic effect or $\pi$-interactions and hydrogen bonding can occur (Koh et al., 2020a). According to Ross \& Subramanian, contributions to positive entropy and enthalpy changes may arise from ionic and hydrophobic effect, while negative enthalpy and entropy changes arise from van der Waals interactions and hydrogen-bond formation. Additionally, enthalpy changes non-significantly positive or negative could be an indication of electrostatic interactions (Ross \& Subramanian, 1981).

Analysis of the thermodynamic contributions for all systems indicated a negative enthalpy contribution from -9 to $-1.2 \mathrm{~kJ} \mathrm{~mol}^{-1}$, suggesting that these interactions were exothermic. These values were significantly higher for fractions with lower degrees of methylation, suggesting the impact of the pectic polysaccharides esterification pattern for enthalpy changes. Hydrogen bonding and van der Waals interactions might contribute to these interactions, but also electrostatic forces, especially under the $\mathrm{pH}$ tested. As previously stated, at this $\mathrm{pH}$, the negatively charged pectic polysaccharides and the positively charged flavylium cation could favor the electrostatic binding.

Moreover, a negative $-\mathrm{T} \Delta \mathrm{S}$ term for all pectic polysaccharides fractions could be observed ( $-\mathrm{T} \Delta \mathrm{S}$ from -16 to $-11 \mathrm{~kJ} \mathrm{~mol}^{-1}$ ), being also an indication of the existence of hydrophobic effect or $\pi$-interaction. However, no significant differences could be observed between pectic polysaccharides. The presence of aromatic rings in cyanidin-3-O-glucoside could explain the occurrence of hydrophobic contacts between anthocyanins and pectic polysaccharides structure On the other hand, entropy can also be a result of other sources such as mixing (expansion of polymers), desolvation entropy due to release of water or conformational changes (Frazier et al., 2010).

Additionally, the entropy parameter for the $70 \%$ methylesterified fractions, was higher than the enthalpy values, which could be an indication that interaction was driven mostly by entropy, compared to enthalpy, indicating the role of the hydrophobic effect in these less polar pectin structures. However, this impact should be small as in a previous work related to cy3gcl binding to human serum albumin where the entropy value was the main driving force for the anthocyanin-protein interactions, the $-\mathrm{T} \Delta \mathrm{S}$ term reported was much higher $(-75.2 \mathrm{~kJ}$ $\mathrm{mol}^{-1}$ ) (Cahyana et al., 2013).

In the case of the interaction between cyanidin-3-O-glucoside and low methylated pectic polysaccharides fractions (HG 30\% and AHG $30 \%$ ), although these interactions were also found to present an entropic contribution (positive $\Delta S$ values), a relative higher contribution of the enthalpy change $\left(-9 \mathrm{~kJ} \mathrm{~mol}^{-1}\right)$ could possibly account for the one and two-orders of magnitude difference in the binding constants compared with the high methyl-esterified pectic polysaccharides. In the former 
pectic polysaccharides, the key structural difference is the higher number of free carboxylic groups. As more free carboxylic groups are available to participate in hydrogen bonding and electrostatic interactions, a stronger binding with cyanidin-3-O-glucoside could be observed, compared to high methylesterified fractions.

All together, these results seem to indicate that these bindings resulted from a combination of favorable electrostatic interactions, hydrogen bonding, and hydrophobic effect or $\pi$-interaction between cy3glc aromatic rings and pectin structure. It could be observed that the relative major driving force depended on the anthocyanin-pectic polysaccharide pair and that they can interact by different mechanisms depending on the degree of methylesterification of pectic polysaccharides. For instance, for high methylated pectic polysaccharides, entropic phenomena seemed to slightly overcome enthalpic ones, compared to low methylesterified fraction (HG 30\%) (-12 vs $-4 \mathrm{~kJ}$ $\mathrm{mol}^{-1}$ and $-15 v s-1.2 \mathrm{~kJ} \mathrm{~mol}^{-1}$ for HG-B and HG-R 70\%, respectively). It could also be observed that the strength of these interaction was also dependent on the anthocyanin-pectic polysaccharide pair with this affecting the binding affinity.

\section{2. ${ }^{1} \mathrm{H}$ NMR experiments}

Cyanidin-3-O-glucoside-pectic polysaccharide molecular interactions were also studied by ${ }^{1} \mathrm{H}$ NMR spectroscopy, following the chemical shift variation of cy3glc protons as a function of pectic polysaccharides-anthocyanins molar ratio. These experiments were performed in order to discriminate the binding with the different anthocyanin equilibrium forms present in solution (essentially the flavylium cation and the hemiketal equilibrium forms). The experimental data was fitted through a model considering the binding equilibria at $n$ multiple equivalents sites, with this analysis allowing to obtain some crucial physico-chemical parameters such as the dissociation constants $\left(K_{\mathrm{d}}\right)$ and maximum chemical shift changes $\left(\Delta \delta_{\max }\right)$. This allowed the establishment of an affinity scale for the anthocyanin-pectic polysaccharide binding. This model was chosen instead of a 1:1 binding interaction as the experimental data was better fitted with a multiple equivalents binding site $\left(\chi^{2} 10^{-6}\right.$ and $10^{-4}$ for multiple and single binding model, respectively). The single model is only valid if the chemical shift variation is affected by a single binding interaction. In this particular binding system, anthocyanin protons can possibly bind at many different sites and therefore a single binding is not likely to be suitable (Murray, Williamson, Lilley, \& Haslam, 1994). Fig. 3 shows the ${ }^{1} \mathrm{H}$ NMR spectra of $1.0 \mathrm{mM}$ cy3glc solution at pD 3.4, evidencing the resonance signals related to the presence of the flavylium cation $\left(\mathrm{AH}^{+}\right)$ and hemiketal equilibrium (B) forms coexisting in solution. Lower intensity peaks can also be observed, corresponding to the other anthocyanin equilibrium forms (cis- and trans-chalcones). The NMR data is consistent with the data already published (Fernandes, Brás et al., 2014; Fernandes, Ivanova, 2014), and the assignment of the different anthocyanin equilibrium forms is presented in this figure. As pectic

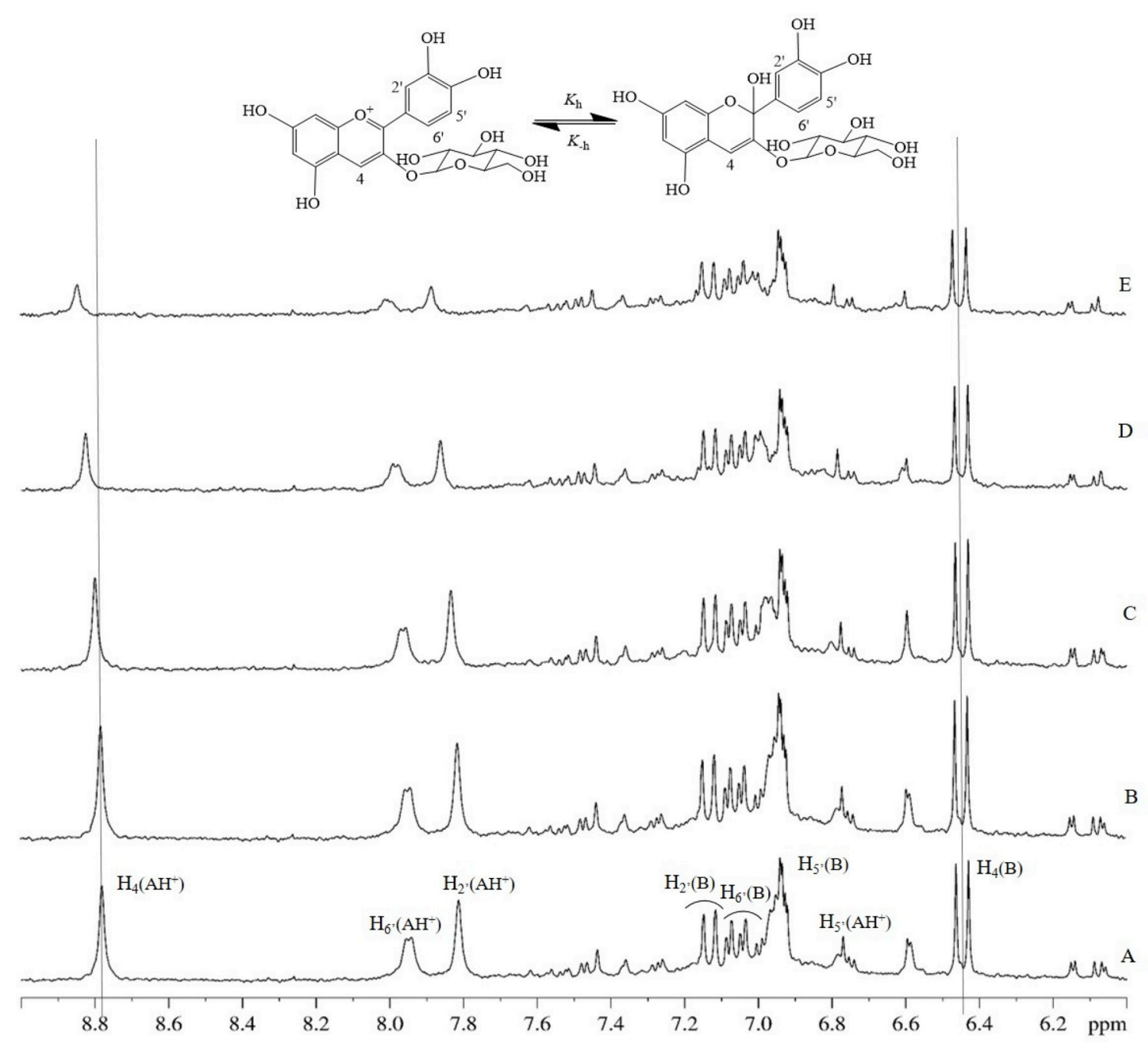

Fig. 3. ${ }^{1} \mathrm{H}$ NMR spectra region $(9.0-6.0 \mathrm{ppm})$ of a $1.0 \mathrm{mM}$ cyanidin-3-O-glucoside solution at $\mathrm{pD} 3.4$ evidencing the different equilibrium forms and the chemical shift displacement in the absence $(A)$ and in the presence of increasing concentrations of HG $30 \%(B-E)$. 
polysaccharides were independently added to the cy3glc solution, the ${ }^{1} \mathrm{H}$ resonance signals of the flavylium cation $\left(\mathrm{H}_{4}, \mathrm{H}_{2}, \mathrm{H}_{5}, \mathrm{H}_{6}\right.$, and $\left.\mathrm{H}_{1^{\prime \prime}}\right)$ were systematically shifted to high frequency fields (although at different extents), progressively broadened and almost disappeared. For instance, for low methylesterified fractions (HG and AHG 30\%), while $\mathrm{H}_{4}$ and $\mathrm{H}_{2}$, showed an average shift of about $0.1 \mathrm{ppm}, \mathrm{H}_{5}$, evidenced a much lower chemical shift displacement $(\approx 0.035 \mathrm{ppm})$. Anomeric glucose proton $\left(\mathrm{H}_{1^{\prime \prime}}\right)$ showed a similar chemical shift displacement, $(\approx 0.030 \mathrm{ppm})$. The high frequency chemical shift could be attributed to the decrease of the electron density around the nucleus due to the occurrence of electrostatic interactions between the positively charged flavylium cation and pectic polysaccharides free carboxylic groups, negatively charged, at this $\mathrm{pH}$. Also, from these results it can be assumed that both anthocyanin chromophore and glucose moiety can participate in this binding, where H-bonding between $\mathrm{OH}$ groups can also be strengthening these interactions.

Additionally, the chemical shift of the protons belonging to other anthocyanin equilibrium forms coexisting in solution (B, Cc and $\mathrm{C} t$ ) were almost unchanged during the titration experiments, which reinforces the preferential interaction between pectic polysaccharides and anthocyanins' flavylium cation form. In fact, only for the $\mathrm{H}_{4}$ proton of cy3glc hemiketal equilibrium form a very small high-frequency shift displacement could be observed probably due to the establishment of hydrogen bonding with the pectic polysaccharides ( $\mathrm{Hu}, \mathrm{Xu}, \&$ Cheng, 2012).

For the high methylesterified fractions (HG-B and HG-R 70\%), similar chemical shift displacements could be observed, although at smaller extent.

Fig. 4 shows the observed chemical shift variations $(\Delta \delta)$ of the $\mathrm{H}_{4}$ proton $\left(\mathrm{AH}^{+}\right)$as the pectic polysaccharide fractions were independently added and their fitting (lines), with $K_{\mathrm{d}}, n$ and $\Delta \delta_{\max }$ being the adjustable parameters. This fitting was also carried out for other available proton titration curves $\left(\mathrm{H}_{2}, \mathrm{H}_{6}\right.$, and $\mathrm{H}_{5}$, ) and provided a reasonable consistent value for the determined parameters across all protons. The best $K_{d}$ and $\Delta \delta_{\max }$ values obtained for the experimental points fitting of cy3glc $\mathrm{H}_{4}$ flavylium cation proton is reported in Table 2 . There was a reasonable agreement between observed and fitted chemical shift changes, which seems to indicate that the binding model was satisfactory for these protons. In fact, $\chi^{2}$ values obtained from the least-squares fitting of eq. (2) to the chemical shift data were small, of $10^{-5}-10^{-6}$, showing the goodness of the fit. The binding curves did not reach saturation due to the limited pectic polysaccharide/anthocyanin molar ratio tested. In fact, these titrations were limited by the ratio flavylium cation proton signal to noise, which did not allow the correct determination of the chemical shift variation of $\mathrm{AH}^{+}$proton signals. In addition, for $\mathrm{HG} 30 \%$ and AHG 3\% fractions, the decrease of $\mathrm{AH}^{+}$signals could also be accompanied by precipitation in the NMR tube, although much slower for AHG fraction. The dissociation constants $\left(K_{\mathrm{d}}\right)$ obtained $\left(K_{\mathrm{a}}=1 / K_{\mathrm{d}}\right)$, allowed the establishment of an affinity scale, evidencing as in the ITC experiments, a higher binding affinity for low methylesterified pectic polysaccharides, followed by high methylesterified pectic polysaccharides $(\mathrm{HG} 30 \%>$ AHG $30 \%>$ HG-B $70 \% \approx$ HB-R $70 \%$ ).

Table 2

Dissociation constant $\left(K_{\mathrm{d}}\right)$, association constant $\left(K_{\mathrm{a}}\right)$, maximum chemical shift displacement $\left(\Delta \delta_{\max }\right)$ and $\chi^{2}$ (difference between the experimental points and the numeric values extracted from a theoretical curve) for cy3glc (1.0 mM)pectic polysaccharides interactions obtained from the fitting of the experimental chemical shift variation of cy3glc $\mathrm{H}_{4}\left(\mathrm{AH}^{+}\right)$, using equation (2).

\begin{tabular}{lllll}
\hline & $K_{\mathrm{d}}(\mathrm{M})$ & $K_{\mathrm{a}}\left(\mathrm{M}^{-1}\right)$ & $\Delta \delta_{\max }(\mathrm{ppm})$ & $\chi^{2}$ \\
\hline HG 30\% & $6.80 \times 10^{-5}$ & $1.47 \times 10^{4}$ & 0.096 & $3.28 \times 10^{-6}$ \\
AHG 30\% & $1.96 \times 10^{-4}$ & $5.09 \times 10^{3}$ & 0.094 & $4.30 \times 10^{-5}$ \\
HG-B 70\% & $1.03 \times 10^{-3}$ & $9.04 \times 10^{2}$ & 0.053 & $4.98 \times 10^{-6}$ \\
HG-R 70\% & $5.50 \times 10^{-3}$ & $1.80 \times 10^{2}$ & 0.13 & $7.15 \times 10^{-6}$ \\
\hline
\end{tabular}

B)
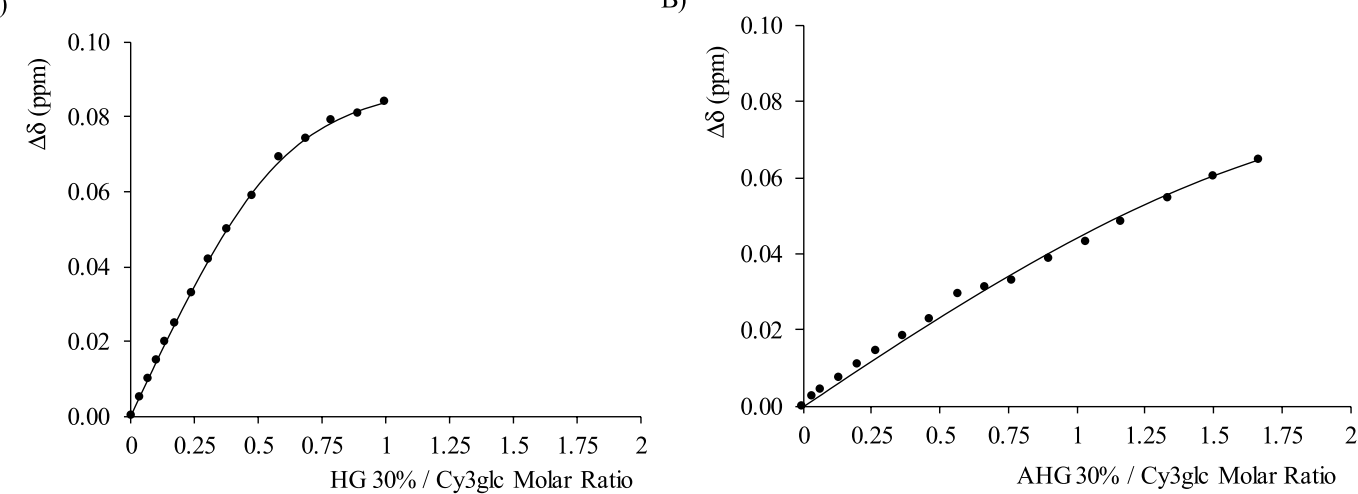

D)

C)

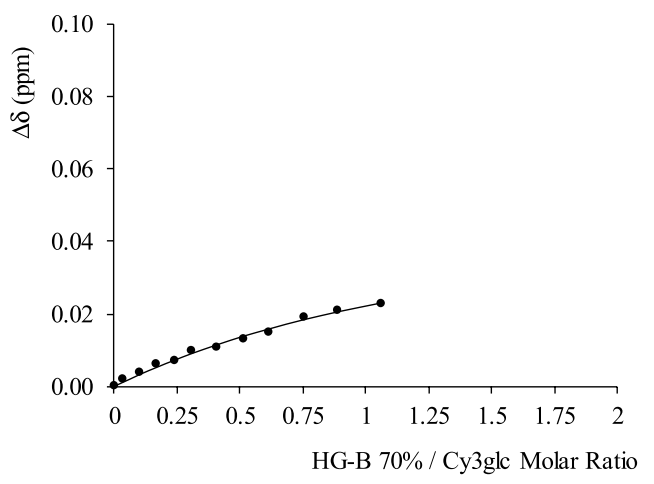

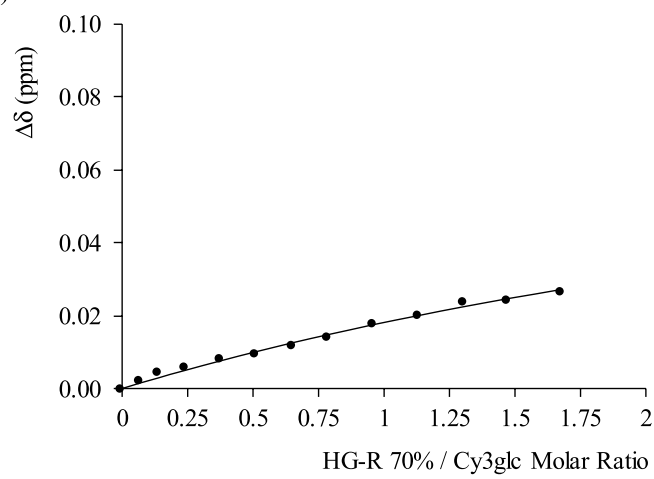

Fig. 4. ${ }^{1} \mathrm{H}$ NMR titration of cyanidin-3-O-glucoside $(1.0 \mathrm{mM})$ with the different homogalacturonans fractions (24 mM galacturonic acid equivalents). Comparison of the observed (symbols) and fitted (line) chemical shifts differences of cy3glc $\mathrm{H}_{4}$ proton (using equation (2)), at pH 3.4 and 298.15 K. A) HG 30\%; B) AHG 30\% C) HGB 70\%; D) HG-R 70\%. 
Additionally, for the amidated fraction it could be observed a much slower decrease in the intensity of cy3glc flavylium cation resonance signals, which only occurred at higher amounts of AHG 30\%. This could probably be due to the electrostatic repulsion between the positively charged flavylium cation and the amide pectic substituent, which is also positively charged at this $\mathrm{pH}$. Compared to the $K_{\mathrm{a}}$ values published in the literature for procyanidins-pectin interaction, the association constants determined for cy3glc interaction with high methyl esterified fractions were lower, reflecting the minor binding affinity of these specific type of pectin structure to cy3glc at $\mathrm{pH} 3.4$.

\subsection{UV-visible spectral measurements}

To evaluate the effect of pectic polysaccharides fortification on cyanidin-3-O-glucoside colour, the visible absorption spectra of this anthocyanin was characterized at pH 3.4 in citrate buffer. Fig. 5 shows the variations of cy3glc spectra with increasing concentration of the four polysaccharide fractions from 2 to $15 \mathrm{mM}$ galacturonic acid equivalents. Absorbance of cy3glc solution generally increased with pectic polysaccharides concentration. However, unlike typical anthocyanin copigmentation, the interaction of cy3glc with these polysaccharides did not trigger spectacular spectral changes. For instance, for all fractions tested, no change in the maximal wavelength of visible absorption $\left(\lambda_{\max }\right)$ could be observed. Additionally, a detailed analysis of the effect of each individual pectic polysaccharides spectra revealed slight differences among each sample, confirming the distinct binding affinity for these fractions observed in the ITC and NMR experiments. For instance, low methyl esterified fractions showed a higher hyperchromic effect, compared to the high methyl esterified fractions. These same experiments were performed at a higher concentration of salts (citrate buffer at

A)

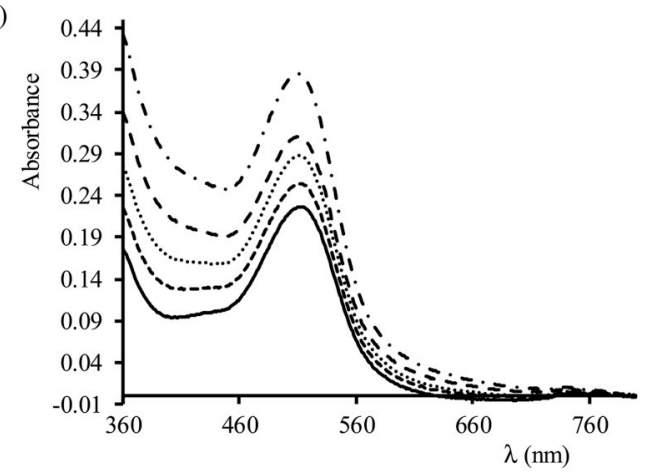

C)

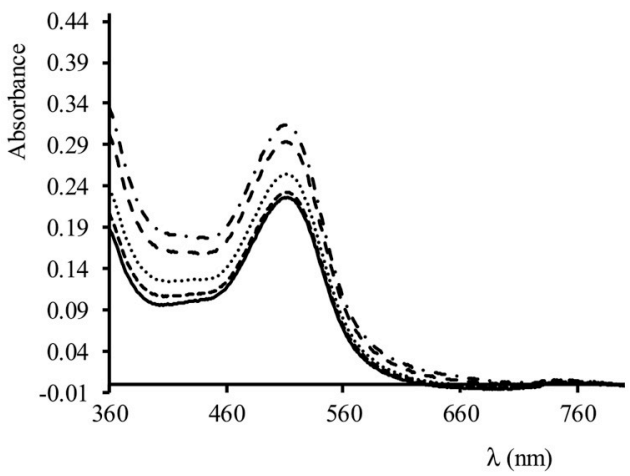

$200 \mathrm{mM}$ ), resulting in a slightly lower hyperchromic effect (21\% vrs $33 \%$, absorbance increase, for $200 \mathrm{mM}$ and $10 \mathrm{mM}$ citrate buffer, respectively). The improved anthocyanin red colour stabilization observed with decreasing degree of methylesterification indicate the role of free GalpA units (Buchweitz et al., 2013a), fundamental for the establishment of electrostatic interactions and for hydrogen bonding between anthocyanin and pectic polysaccharides hydroxyl groups. Depending on the number of hydroxyl groups in the anthocyanin B-ring and the pectin structure, one, two or even three hydrogen bonds may be formed, leading to successively increasing stabilization (Buchweitz et al., 2013a; Fernandes, Brás et al., 2014; ). Additionally, the possible occurrence of anthocyanin adsorption onto pectin structure could also explain the hyperchromic shift, as the polysaccharide can create a kind of nucleation site for anthocyanin adsorption, causing the protection of the chromophore against water addition. Malvidin-3-O-glucoside, a major red wine anthocyanin, also evidenced a slight hyperchromic effect in the presence of a low methoxylated commercial citrus pectin (Fernandes et al., 2016). In agreement with the small spectral changes observed, this binding did not significantly affect the thermodynamic constants of the acid-base and hydration equilibria. The hyperchromic effect was also noticed after anthocyanins interaction with highly methylated apple pectins, whereas an opposite effect (weak hypochromic effect) was observed for the interaction with cellulose, oat bran, and lignin (Mazzaracchio, Pifferi, Kindt, Munyaneza, \& Barbiroli, 2004). On the other hand, sugar beet pectins promoted a strong bathochromic effect with blackcurrant anthocyanins, with this effect being attributed to the endogenous iron ions (bound to the polysaccharide structure) (Buchweitz, Carle, \& Kammerer, 2012).

Regarding high methylesterified pectic polysaccharides (HG-B and HG-R 70\%), a smaller hyperchromic effect was observed and when

B)

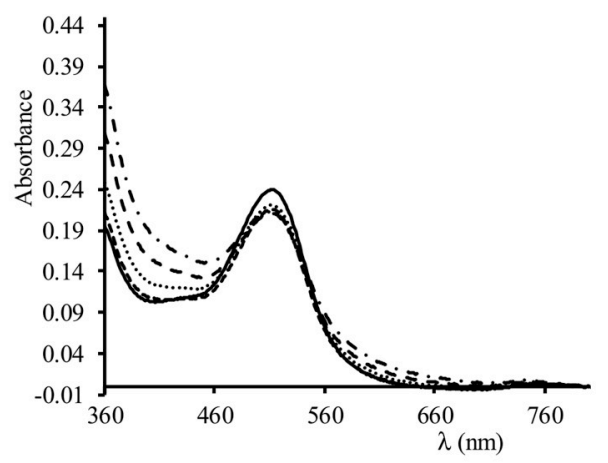

D)

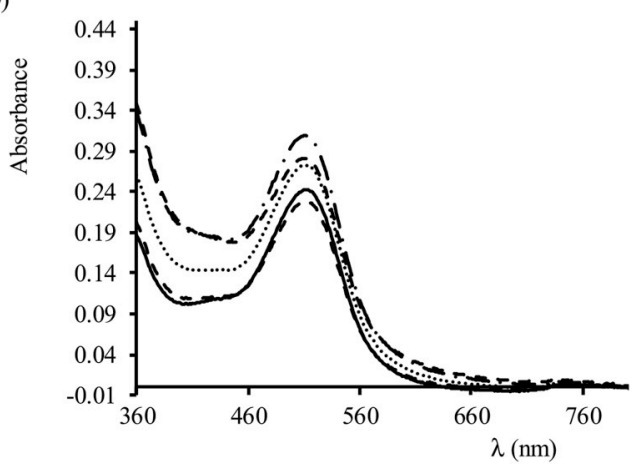

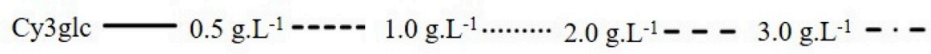

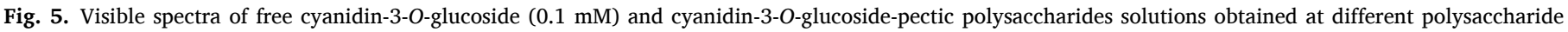
concentrations, at pH 3.4 and $25{ }^{\circ} \mathrm{C}$; A) HG 30\%, B) AHG 30\%, C) HG-B 70\%, D) HG-R 70\%. 
comparing the two high methylesterified pectic polysaccharide fractions, slightly different behaviors could be noticed concerning the different distribution of free and esterified carboxylic groups. While blockwise esterification resulted in a higher hyperchromic effect (28\%, absorbance increased from control sample, cy3glc), random distribution caused a smaller hyperchromic effect ( $14 \%$ absorbance increased from control sample, cy3glc), in accordance to the lower binding affinity observed for this HG fractions by ICT and NMR. In the case of the blockwise methylesterified fraction, the higher density of free carboxylic groups distributed in a blockwise manner, may contribute to the enhanced anthocyanin stabilization, probably due to the possibility of preferable anthocyanin stacking.

In the case of the amidated fraction (AHG), the stronger binding affinities detected by ITC and NMR, did not result in a red colour improvement with the increase of concentration of this pectic polysaccharide. This behavior could be due to the presence of amide groups which are protonated at $\mathrm{pH}$ 3.4. Thus, the distribution of some positive charges along pectin molecule could increase the repulsive forces lowering the stability of the positively charged flavylium cation.

All together it could be hypothesized that in cy3glc-pectic polysaccharides binding, at $\mathrm{pH} 3.4$ electrostatic interactions are the predominant and the first interaction established. These interactions can be further stabilized and reinforced through hydrogen bonds and hydrophobic effect.

\section{Conclusions}

The role of methyl-esterification degree and amidation of pectic polysaccharides on the association with cyanidin-3-O-glucoside was demonstrated. These interactions occur through the establishment of electrostatic interactions and are further stabilized through hydrogen bonding and hydrophobic effect. Depending on each anthocyanin-pectic polysaccharide pair, different binding affinities could be observed with these interactions being governed by distinct mechanisms. The lower the degree of methyl-esterification, the higher the energy released during titration and higher binding affinities could be observed. An affinity scale could be obtained and in the order: HG 30\% > AHG 30\% > HG-B $70 \% \approx$ HG-R $70 \%$. For more hydrophobic pectin structures these interactions seemed to be ruled essentially through hydrophobic effect.

Due to anthocyanin/pectic polysaccharide interactions, cy3glc red colour could be improved polysaccharides, although amidation seemed to result on a lower stabilization of the flavylium cation. This knowledge may further help investigations regarding the possible use of pectic polysaccharides for anthocyanin colour modulation and for the development of functional food ingredients.

\section{Author statement}

The authors have chosen not to specify which data has been used.

\section{Declaration of competing interest}

The authors declare no conflict of interest.

\section{Acknowledgements}

This research was supported by a research project grant (PTDC/AGRTEC/2789/2014) with financial support from FCT/MEC through national funds and co-financed by FEDER, under the Partnership Agreement PT2020 (UID/QUI/50006/2019 - POCI/01/0145/FEDER/ 007265).

Ana Fernandes and Joana Oliveira gratefully acknowledges the PostDoctoral grant from FCT (SFRH/BPD/112465/2015) and the IF starting grants from FCT (IF/00225/2015), respectively.

Frederico Ferreira-da-Silva was financed by FEDER - Fundo Europeu de Desenvolvimento Regional funds through the COMPETE 2020 Operacional Programme for Competitiveness and Internationalisation (POCI), Portugal 2020, and by Portuguese funds through FCT - Fundação para a Ciência e a Tecnologia/Ministério da Ciência, Tecnologia e Ensino Superior in the framework of the project "Institute for Research and Innovation in Health Sciences" (POCI-01-0145-FEDER-007274). Fátima Fonseca financed by the project Norte-01-0145-FEDER-000008 Porto Neurosciences and Neurologic Disease Research Initiative at I3S, supported by Norte Portugal Regional Operational Programme (NORTE 2020), under the PORTUGAL 2020 Partnership Agreement, through the European Regional Development Fund (FEDER).

\section{Appendix A. Supplementary data}

Supplementary data to this article can be found online at https://doi.org/10.1016/j.foodhyd.2019.105625.

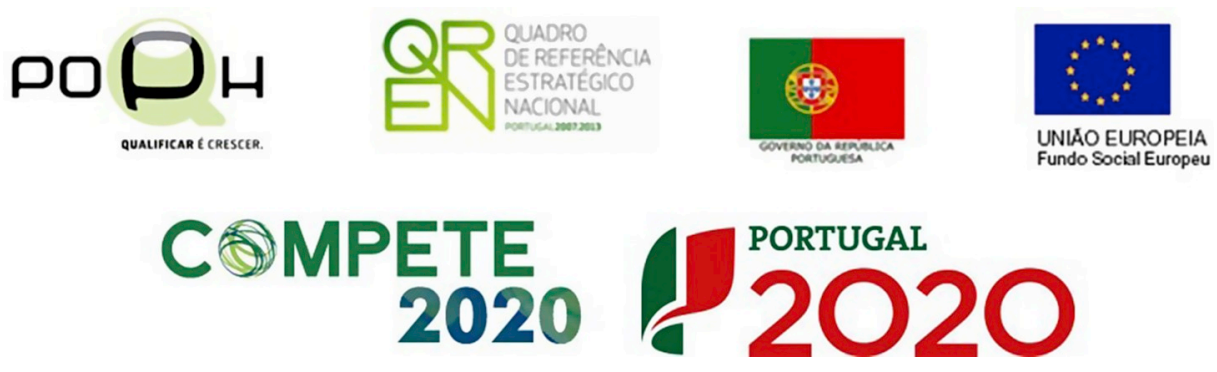

\section{References}

Brautigam, C. A. (2015). Chapter five - calculations and publication-quality illustrations for analytical ultracentrifugation data. In J. L. Cole (Ed.), Methods in enzymology (Vol. 562, pp. 109-133). Academic Press.

Brouillard, R. (1982). Chemical structure of anthocyanins. In P. Markakis (Ed.), Anthocyanins as food colors (pp. 1-40). Academic Press.
Brouillard, R., \& Delaporte, B. (1977). Chemistry of anthocyanin pigments. 2. Kinetic and thermodynamic study of proton transfer, hydration, and tautomeric reactions of malvidin 3-glucoside. Journal of the American Chemical Society, 99(26), 8461-8468. Buchweitz, M., Carle, R., \& Kammerer, D. R. (2012). Bathochromic and stabilising effects of sugar beet pectin and an isolated pectic fraction on anthocyanins exhibiting pyrogallol and catechol moieties. Food Chemistry, 135(4), 3010-3019.

Buchweitz, M., Speth, M., Kammerer, D. R., \& Carle, R. (2013). Impact of pectin type on the storage stability of black currant (Ribes nigrum L.) anthocyanins in pectic model solutions. Food Chemistry, 139(1-4), 1168-1178. 
Buchweitz, M., Speth, M., Kammerer, D. R., \& Carle, R. (2013). Stabilisation of strawberry (Fragaria $x$ ananassa Duch.) anthocyanins by different pectins. Food Chemistry, 141(3), 2998-3006.

Caffall, K. H., \& Mohnen, D. (2009). The structure, function, and biosynthesis of plant cell wall pectic polysaccharides. Carbohydrate Research, 344(14), 1879-1900.

Cahyana, Y., \& Gordon, M. H. (2013). Interaction of anthocyanins with human serum albumin: Influence of pH and chemical structure on binding. Food Chemistry, 141(3) 2278-2285.

Cameron, R. G., Chau, H. K., Hotchkiss, A. T., \& Manthey, J. A. (2017). Release and recovery of pectic hydrocolloids and phenolics from culled citrus fruits. Food Hydrocolloids, 72, 52-61.

Charlton, A. J., Baxter, N. J., Khan, M. L., Moir, A. J. G., Haslam, E.Davies, A. P., .. (2002). Polyphenol/peptide binding and precipitation. Journal of Agricultural and Food Chemistry, 50(6), 1593-1601.

Dangles, O., \& Fenger, J.-A. (2018). The chemical reactivity of anthocyanins and its consequences in food science and nutrition. Molecules, 23(8), 1970.

De Ruiter, G. A., Schols, H. A., Voragen, A. G. J., \& Rombouts, F. M. (1992). Carbohydrate analysis of water-soluble uronic acid-containing polysaccharides with high-performance anion-exchange chromatography using methanolysis combined with TFA hydrolysis is superior to four other methods. Analytical Biochemistry, 207 (1), 176-185.

De Vries, J. A., Rombouts, F. M., Voragen, A. G. J., \& Pilnik, W. (1982). Enzymic degradation of apple pectins. Carbohydrate Polymers, 2(1), 25-33.

Englyst, H. N., \& Cummings, J. H. (1984). Simplified method for the measurement of total non-starch polysaccharides by gas-liquid chromatography of constituent sugars as alditol acetates. Analyst, 109(7), 937-942.

Ersus, S., \& Yurdagel, U. (2007). Microencapsulation of anthocyanin pigments of black carrot (Daucuscarota L.) by spray drier. Journal of Food Engineering, 80(3), 805-812.

Fernandes, A., Brás, N. F., Mateus, N., \& de Freitas, V. (2014). Understanding the molecular mechanism of anthocyanin binding to pectin. Langmuir, 30(28), 8516-8527.

Fernandes, A., Brás, N. F., Oliveira, J., Mateus, N., \& de Freitas, V. (2016). Impact of a pectic polysaccharide on oenin copigmentation mechanism. Food Chemistry, 209, 17-26.

Fernandes, A., Ivanova, G., Brás, N. F., Mateus, N., Ramos, M. J.Rangel, M., ... (2014). Structural characterization of inclusion complexes between cyanidin-3-O-glucoside and $\beta$-cyclodextrin. Carbohydrate Polymers, 102, 269-277, 0.

Fernández-López, J. A., Angosto, J. M., Giménez, P. J., \& León, G. (2013). Thermal stability of selected natural red extracts used as food colorants. Plant Foods for Human Nutrition, 68(1), 11-17.

Frazier, R. A., Deaville, E. R., Green, R. J., Stringano, E., Willoughby, I.Plant, J., .. (2010). Interactions of tea tannins and condensed tannins with proteins. Journal of Pharmaceutical and Biomedical Analysis, 51(2), 490-495.

Frazier, R. A., Papadopoulou, A., Mueller-Harvey, I., Kissoon, D., \& Green, R. J. (2003). Probing Protein-Tannin interactions by isothermal titration microcalorimetry. Journal of Agricultural and Food Chemistry, 51(18), 5189-5195.

Hernández-Hierro, J. M., Quijada-Morín, N., Martínez-Lapuente, L., Guadalupe, Z., Ayestarán, B.Rivas-Gonzalo, J. C., ... (2014). Relationship between skin cell wall composition and anthocyanin extractability of Vitis vinifera L. cv. Tempranillo at different grape ripeness degree. Food Chemistry, 146, 41-47, 0.

Hu, J., Xu, T., \& Cheng, Y. (2012). NMR insights into dendrimer-based host-guest systems. Chemical Reviews, 112(7), 3856-3891.

Keller, S., Vargas, C., Zhao, H.-T., Piszczek, G., Brautigam, C. A., \& Schuck, P. (2012). High-Precision isothermal titration calorimetry with automated peak-shape analysis. Analytical Chemistry, 84(11), 5066-5073.

Koh, J., Xu, Z., \& Wicker, L. (2020). Binding kinetics of blueberry pectin-anthocyanins and stabilization by non-covalent interactions. Food Hydrocolloids, 99, 105354.

Koh, J., Xu, Z., \& Wicker, L. (2020). Blueberry pectin and increased anthocyanins stability under in vitro digestion. Food Chemistry, 302, 125343.
Leydet, Y., Gavara, R., Petrov, V., Diniz, A. M., Parola, A.Lima, J. C., ... (2012). The effect of self-aggregation on the determination of the kinetic and thermodynamic constants of the network of chemical reactions in 3-glucoside anthocyanins. Phytochemistry, 83, 125-135, 0.

Lin, Z., Fischer, J., \& Wicker, L. (2016). Intermolecular binding of blueberry pectin-rich fractions and anthocyanin. Food Chemistry, 194, 986-993.

Mamet, T., Ge, Z., Zhang, Y., \& Li, C. (2018). Interactions between highly galloylated persimmon tannins and pectins. International Journal of Biological Macromolecules, 106, 410-417.

Mazzaracchio, P., Pifferi, P., Kindt, M., Munyaneza, A., \& Barbiroli, G. (2004). Interactions between anthocyanins and organic food molecules in model systems. International Journal of Food Science and Technology, 39(1), 53-59.

Mohnen, D., Doong, R. L., Liljebjelke, K., Fralish, G., \& Chan, J. (2003). Pectin and pectinases. Amsterdam: Elsevier Science.

Mortensen, A., Aguilar, F., Crebelli, R., Di Domenico, A., Dusemund, B.Frutos, M. J., .. (2017). Re-evaluation of pectin (E 440i) and amidated pectin (E 440ii) as food additives. EFSA Journal, 15(7), e04866.

Murray, N. J., Williamson, M. P., Lilley, T. H., \& Haslam, E. (1994). Study of the interaction between salivary proline-rich proteins and a polyphenol by ${ }^{1} \mathrm{H}-\mathrm{NMR}$ spectroscopy. European Journal of Biochemistry, 219, 923-935.

Padayachee, A., Netzel, G., Netzel, M., Day, L., Mikkelsen, D., \& Gidley, M. J. (2013). Lack of release of bound anthocyanins and phenolic acids from carrot plant cell walls and model composites during simulated gastric and small intestinal digestion. Food \& Function, 4(6), 906-916.

Padayachee, A., Netzel, G., Netzel, M., Day, L., Zabaras, D.Mikkelsen, D., ... (2012). Binding of polyphenols to plant cell wall analogues - Part 1: Anthocyanins. Food Chemistry, 134(1), 155-161.

Phan, A. D. T., D'Arcy, B. R., \& Gidley, M. J. (2016). Polyphenol-cellulose interactions: Effects of $\mathrm{pH}$, temperature and salt. International Journal of Food Science and Technology, 51(1), 203-211.

Phan, A. D. T., Flanagan, B. M., D’Arcy, B. R., \& Gidley, M. J. (2017). Binding selectivity of dietary polyphenols to different plant cell wall components: Quantification and mechanism. Food Chemistry, 233, 216-227.

Popov, K., Rönkkömäki, H., \& Lajunen, L. H. J. (2006). Guidelines for NMR measurements for determination of high and low $\mathrm{p} K_{\mathrm{a}}$ values (IUPAC Technical Report). Pure and Applied Chemistry, 78(3), 663-675.

Ross, P. D., \& Subramanian, S. (1981). Thermodynamics of protein association reactions: Forces contributing to stability. Biochemistry, 20(11), 3096-3102.

Scheuermann, T. H., \& Brautigam, C. A. (2015). High-precision, automated integration of multiple isothermal titration calorimetric thermograms: New features of NITPIC. Methods, 76, 87-98.

Thibault, J.-F., Renard, C. M. G. C., Axelos, M. A. V., Roger, P., \& Crépeau, M.-J. (1993). Studies of the length of homogalacturonic regions in pectins by acid hydrolysis. Carbohydrate Research, 238, 271-286.

Turnbull, W. B., \& Daranas, A. H. (2003). On the value of c: can low affinity systems Be studied by isothermal titration calorimetry? Journal of the American Chemical Society, 125(48), 14859-14866.

Voragen, A., Coenen, G.-J., Verhoef, R., \& Schols, H. (2009). Pectin, a versatile polysaccharide present in plant cell walls. Structural Chemistry, 20(2), 263-275.

Watrelot, A. A., Le Bourvellec, C., Imberty, A., \& Renard, C. M. G. C. (2013). Interactions between pectic compounds and procyanidins are influenced by methylation degree and chain length. Biomacromolecules, 14(3), 709-718.

Watrelot, A. A., Le Bourvellec, C., Imberty, A., \& Renard, C. M. G. C. (2014). Neutral sugar side chains of pectins limit interactions with procyanidins. Carbohydrate Polymers, 99, 527-536.

Yapo, B. M., Lerouge, P., Thibault, J.-F., \& Ralet, M.-C. (2007). Pectins from citrus peel cell walls contain homogalacturonans homogenous with respect to molar mass, rhamnogalacturonan I and rhamnogalacturonan II. Carbohydrate Polymers, 69(3), $426-435$. 